\title{
PENINGKATAN HASIL BELAJAR BIOLOGI POKOK BAHASAN SISTEM PENCERNAAN PADA MANUSIA MELALUI PENERAPAN MODEL PEMBELAJARAN TEBAK KATA PADA SISWA KELAS VIII SMP KRISTEN 1 YPK MALANG
}

\author{
Riyanto, Yulianus Ndapa Ate \\ Program Studi Pendidikan Biologi IKIP Budi Utomo Malang \\ Jalan Simpang Arjuno 14-B Malang 65112 \\ E-mail: ryan_kebo@yahoo.com
}

\begin{abstract}
Abstrak: Tujuan penelitian ini untuk mengetahui apakah penerapan model pembelajaran tebak kata dapat meningkatkan hasil belajar Biologi siswa kelas VIII SMP Kristen 1 YPK Malang pada pokok bahasan sistem pencernaan pada manusia. Rancangan penelitian ini adalah Penelitian Tindakan Kelas. Penelitian tindakan kelas ini dilaksanakan dalam 2 siklus, dan setiap siklus merupakan suatu alur proses kegiatan yang meliputi perencanaan, tindakan, pengamatan, dan refleksi. Subjek penelitian adalah seluruh siswa kelas VIII ${ }^{\mathrm{B}}$ SMP Kristen 1 YPK Malang. Penerapan model pembelajaran tebak kata dapat meningkatkan hasil belajar biologi siswa kelas VIII SMP Kristen 1 YPK Malang pada pokok bahasan sistem pencernaan pada manusia. Peningkatan ini ditandai dengan meningkatnya ketuntasan belajar klasikal dari siklus ke siklus, di mana persentase jumlah siswa yang tuntas belajar pada siklus I hanya mencapai $66 \%$, selanjutnya pada siklus II meningkat menjadi $78 \%$ siswa tuntas belajar dan telah mencapai target ketuntasan belajar klasikal minimum $75 \%$.
\end{abstract}

Kata Kunci : Hasil Belajar, Sistem Pencernaan Pada Manusia, Tebak Kata

THE GRADUATION NUMBER WILL REACH STUDIED THE BIOLOGICAL SUBJECTS OF THE GASTROINTESTINAL TRACT IN HUMANS THROUGH THE APPLICATION OF KIND OF CLASSROOM GUESS THE WORD ON STUDENT OF CLASS VIII THE PROTESTANT JUNIOR HIGH SCHOOL 1 YPK MALANG

\begin{abstract}
: the purpose of this research to see if the application of learning model charades can improve learning outcomes biology graders VIII protestant junior high school 1 YPK Malang on the subjects of digestive system in humans. The act of this class research carried out in 2 cycle, and every cycle is a groove process of activities which includes planning, action, observation, and reflection. The application of learning model charades can improve learning outcomes biology graders on the subjects of digestive system in humans. The increase was marked by increasing value learning from the cycle to cycle,
\end{abstract}


in which the percentage of the number of students work completed learn from the cycle I only reached $66 \%$, cycle II on increased to 78 percent of students had been completed learning and is well within range value learn minimum $75 \%$

\section{Keywords: Study Results, Digestive System In Humans, Charades}

Pendidikan merupakan suatu usaha yang dilakukan oleh peserta didik dalam rangka mewujudkan perkembangan fisik, mental, dan spiritualnya, yaitu dengan jalan menempuh suatu proses belajar (Hamalik, 2001). Hasil dari proses pendidikan adalah berupa prestasi dari perkembangan-perkembangan tersebut. Dalam proses pendidikan peran guru begitu menonjol sebagai teladan bagi siswanya. Salah satu peran guru yang sangat penting adalah sebagai motivator dan fasilitator. Sebagai motivator, guru harus mampu menyemangati siswa agar dalam diri siswa tumbuh niat dan motivasi untuk terus belajar. Sedangkan sebagai fasilitator, guru bertindak sebagai individu yang harus mampu menyediakan dan menjembatani segala kebutuhan yang diperlukan dalam proses transfer ilmu pengetahuan (Chatarina, 2007).

Salah satu upaya untuk menjembatani proses pentransferan ilmu pengetahuan tersebut adalah dengan perencanaan suatu program pendidikan, misalnya perencanaan kurikulum pendidikan, kebijakan-kebijakan pemerintah, pengadaan fasilitas pendidikan, pemilihan metode pembelajaran, dan sebagainya. Berdasarkan data observasi awal dengan guru mata pelajaran IPA Biologi diperoleh keterangan tentang kurikulum yang di gunakan, metode pembelajaran, fasilitas yang ada di sekolah, serta kondisi siswa kelas VIII di SMP Kristen 1 YPK Malang. Data yang diperoleh dari observasi awal tersebut menyatakan bahwa metode yang paling sering digunakan guru dalam proses pembelajaran Biologi yaitu metode ceramah bervariasi. Metode tersebut pada dasarnya mentransfer pengetahuan secara utuh pada siswa. Meskipun dianggap baik, tetapi pada kenyataannya sering membuat siswa kurang berkembang karena pembelajaran yang hanya terfokus pada guru.

Pemilihan model pembelajaran yang tepat perlu diupayakan guru untuk memudahkan proses terbentuknya pengetahuan pada siswa, namun guru juga harus memperhatikan apakah model pembelajaran yang digunakan itu penerapannya sudah efektif dan efisien. Salah satu model yang dapat digunakan guru dalam pembelajaran IPA Biologi adalah suatu model pembelajaran permainan, yaitu model pembelajaran yang dilaksanakan dengan langkah bermain. Hakekat pembelajaran permainan ini adalah pembelajaran yang menekankan aspek REACT, yaitu mengaitkan (Relating), mengalami (Experiencing), menerapkan teori pada situasi tertentu (Applying), kerja sama (Cooperating), dan perolehan pengetahuan baru (Tranfering). Bentuk pembelajaran permainan ini adalah tebak kata. Tebak kata ialah salah satu metode pembelajaran menggunakan kartu yaitu ukuran 10x10 cm dan diisi ciri-ciri kata lainnya yang mengarah 
pada jawaban, serta kartu ukuran $5 \times 2 \mathrm{~cm}$ untuk menulis kata/ istilah yang mau ditebak" (Widodo, 2009).

\section{METODE PENELITIAN}

Penelitian ini merupakan penelitian tindakan kelas dengan rancangan yaitu berupa pemberian tindakan pada siklus-siklus pembelajaran. Menurut Arifin (2010:190), penelitian tindakan kelas merupakan salah satu bagian dari penelitian tindakan dengan tujuan untuk memperbaiki atau meningkatkan mutu praktik proses belajar mengajar di kelas atau di luar kelas. Subjek yang diteliti dalam penelitian ini adalah seluruh siswa kelas VIII ${ }^{\mathrm{B}}$ SMP Kristen 1 YPK Malang. Kelas VIII ${ }^{\mathrm{B}}$ terdiri dari 44 siswa, 19 putra dan 25 putri. Peneliti memilih siswa kelas VIII ${ }^{\mathrm{B}}$, karena berdasarkan hasil observasi awal dan informasi yang peneliti dapatkan dari guru mata pelajaran Biologi kelas VIII, diketahui bahwa prestasi belajar mata pelajaran Biologi kelas $\mathrm{VIII}^{\mathrm{B}}$ relatif lebih rendah dibandingkan dengan prestasi belajar mata pelajaran Biologi siswa kelas VIII lainnya.

Penelitian tindakan kelas ini dirancang untuk dilaksanakan dalam dua siklus. Setiap siklus terdiri dari empat tahapan yang harus dijalani, yaitu (1) Perencanaan, berisi rencana tindakan yang akan dilakukan untuk memperbaiki, meningkatkan atau mengubah perilaku dan sikap sebagai solusi. (2) Tindakan, berisi kegiatan yang dilakukan peneliti sebagai upaya perbaikan, peningkatan atau perubahan yang diinginkan. (3) Pengamatan atau observasi, pengamatan atas hasil atau dampak dari tindakan yang dilakukan. (4) Refleksi, peneliti mengkaji, melihat dan mempertimbangkan atas hasil atau dampak dari berbagai kriteria. Tahap-tahap siklus kedua pada dasarnya sama dengan siklus pertama, hanya tindakannya yang berbeda dengan siklus pertama. Penentuan tindakan pada siklus kedua ini didasarkan pada hasil refleksi siklus pertama. Kriteria penilaian hasil belajar individu dalam penelitian ini, sebagai berikut

Tabel 1. Analisis Ketuntasan Belajar Individu

\begin{tabular}{|l|c|l|l|}
\hline \multicolumn{1}{|c|}{ Nilai } & Nilai Huruf & \multicolumn{1}{|c|}{ Keterangan } & \multicolumn{1}{c|}{ Predikat } \\
\hline$>85$ & A & Tuntas & Sangat Baik \\
\hline $75-85$ & B & Tuntas & Baik \\
\hline $65-74$ & C & Tuntas & Cukup \\
\hline $50-64$ & D & Tidak tuntas & Kurang \\
\hline$<50$ & E & Tidak tuntas & Sangat Kurang \\
\hline
\end{tabular}

Selanjutnya, untuk menentukan ketuntasan klasikal, maka peneliti menggunakan rumus (Depdiknas, 2004), sebagai berikut:

$\mathrm{KB}=\frac{\mathrm{FN}}{\sum \mathrm{N}} \times 100 \%$

Keterangan:

$\mathrm{KB}$ : Ketuntasan belajar klasikal

FN : Jumlah siswa tuntas/ tidak tuntas

$\sum \mathrm{N}$ : Jumlah seluruh siswa 
Analisis aktivitas siswa dilakukan dengan menghitung rata-rata keaktifan siswa dalam setiap pembelajaran, dengan rumus sebagai berikut (Depdiknas, 2004):

$\overline{\mathrm{x}}=\frac{\sum \mathrm{x}}{\mathrm{N}}$

Keterangan:

$\overline{\mathrm{x}} \quad$ : Rata-rata keaktifan siswa

$\sum \mathrm{x}:$ Jumlah siswa yang aktif

$\mathrm{N} \quad$ : Jumlah seluruh siswa

\section{HASIL DAN PEMBAHASAN}

Berdasarkan data hasil belajar Biologi konsep sistem pencernaan pada manusia dapat dikelompokkan kategori hasil belajar siswa seperti pada Tabel berikut ini.

Tabel 2. Ketuntasan Belajar Klasikal Siklus I

\begin{tabular}{|c|c|c|c|c|}
\hline Kategori & $\mathbf{N}$ & Persentase & $\begin{array}{l}\text { Akumulasi } \\
\text { Ketuntasan }\end{array}$ & T/TT \\
\hline Sangat baik & 4 & $9 \%$ & $9 \%$ & \multirow{3}{*}{29 siswa tuntas } \\
\hline Baik & 11 & $25 \%$ & $25 \%$ & \\
\hline Cukup & 14 & $32 \%$ & $32 \%$ & \\
\hline Kurang & 7 & $16 \%$ & - & \multirow{2}{*}{15 siswa tidak tuntas } \\
\hline Sangat kurang & 8 & $18 \%$ & - & \\
\hline Total & 44 & $100 \%$ & $66 \%$ & \\
\hline
\end{tabular}

Keterangan:

$\mathrm{N}=$ Jumlah siswa

$\mathrm{T}=$ Tuntas

$\mathrm{TT}=$ Tidak tuntas

Berdasarkan data pada tabel di atas, diketahui ketuntasan belajar klasikal siklus I adalah $66 \%$, dengan perhitungan, yaitu:

K B $=\frac{\text { Jumlah Siswa Tuntas }}{\text { Jumlah Seluruh Siswa }} \times 100 \%$

$=\frac{29}{44} \times 100 \%$

$=66 \%$

Secara umum dapat disimpulkan bahwa hasil penelitian tindakan kelas pada siklus I, untuk ketuntasan secara klasikal termasuk ke dalam kategori 'Cukup' karena mencapai $66 \%$, namun belum mencapai target ketuntasan klasikal minimal 75\%, oleh karena itu peneliti melanjutkan tindakan pada siklus II. Data tentang aktivitas siswa selama proses pembelajaran pada siklus I diperoleh melalui observasi, dan hasilnya dapat dilihat pada Tabel berikut ini. 
Tabel 3. Hasil Observasi Keaktifan Siswa Siklus I

\begin{tabular}{|l|l|l|}
\hline \multirow{2}{*}{ Aspek Aktivitas } & Jumlah Siswa \\
\cline { 2 - 3 } & Aktif & Tidak Aktif \\
\hline Aktifitas dalam bertanya & 18 siswa & 26 siswa \\
\hline Aktifitas dalam menjawab & 26 siswa & 18 siswa \\
\hline Aktifitas dalam berpendapat & 12 siswa & 32 siswa \\
\hline Aktifitas dalam merangkum & 32 siswa & 12 siswa \\
\hline Rata-rata & $\mathbf{2 2}$ & $\mathbf{2 2}$ \\
\hline Rata-rata persentase & $\mathbf{5 0 \%}$ & $\mathbf{5 0 \%}$ \\
\hline
\end{tabular}

Berdasarkan data yang tercantum pada tabel di atas dapat disimpulkan bahwa selama kegiatan pembelajaran, siswa kurang aktif. Persentase siswa yang aktif dan yang tidak aktif dalam pembelajaran sama, yaitu 50\%. Hal ini disebabkan karena masih banyak siswa yang kurang aktif dalam bertanya, mengemukakan pendapat, maupun menjawab pertanyaan dari guru, karena siswa terlihat masih-masih ragu-ragu, takut atau malu untuk melakukannya sebab guru tidak menunjuk salah satu siswa untuk bertanya, mengemukakan pendapat, maupun menjawab pertanyaan yang disampaikan, jadi siswa secara mandiri diminta melakukannya menurut kesadaran, permasalahan, dan inisiatif mereka sendiri. Hal inilah yang menjadi pemicu keragu-raguan siswa untuk bertanya, berpendapat, dan menjawab pertanyaan karena mereka merasa tidak diberi beban oleh guru untuk melakukannya. Sesuai dengan uraian tersebut, maka peneliti berkesimpulan bahwa tindakan lanjutan harus diberikan pada siswa melalui pelaksanaan pembelajaran siklus II.

Berdasarkan data hasil belajar mata pelajaran Biologi konsep sistem pencernaan pada manusia dapat dikelompokkan kategori hasil belajar siswa seperti pada Tabel di bawah ini.

Tabel 4. Ketuntasan Belajar Klasikal Siklus I

\begin{tabular}{|l|l|l|l|l|}
\hline Kategori & $\mathrm{N}$ & Persentase & $\begin{array}{l}\text { Akumulasi } \\
\text { Ketuntasan }\end{array}$ & T/TT \\
\hline Sangat baik & 7 & $16 \%$ & $16 \%$ & \multirow{2}{*}{34 siswa tuntas } \\
\hline Baik & 14 & $32 \%$ & $32 \%$ & \multirow{2}{*}{ 10 siswa tidak tuntas } \\
\cline { 1 - 4 } Cukup & 13 & $30 \%$ & $30 \%$ & \\
\hline Kurang & 7 & $16 \%$ & - & \\
\hline Sangat kurang & 3 & $7 \%$ & - & \\
\hline Total & 44 & $100 \%$ & $78 \%$ & \\
\hline
\end{tabular}

Keterangan:

$\mathrm{N}=$ Jumlah siswa

$\mathrm{T}=$ Tuntas

$\mathrm{TT}=$ Tidak tuntas

Berdasarkan data pada tabel di atas, diketahui ketuntasan belajar klasikal siklus II adalah $78 \%$, dengan perhitungan, yaitu:

K B $=\frac{\text { Jumlah Siswa Tuntas }}{\text { Jumlah Seluruh Siswa }} \times 100 \%$ 
$=\frac{34}{44} \times 100 \%$

$=78 \%$

Berdasarkan hasil belajar siswa tersebut, maka dapat disimpulkan bahwa pelaksanaan tindakan siklus II pada siswa kelas VIII SMP Kristen 1 YPK Malang telah berhasil karena persentase ketuntasan belajar klasikal mencapai 78\%, di mana persentase ketuntasan ini telah melewati standar ketuntasan klasikal minimal 75\%, sehingga penelitian dapat dihentikan. Data tentang aktivitas siswa selama proses pembelajaran pada siklus II diperoleh melalui observasi, dan hasilnya dapat dilihat pada Tabel berikut ini.

Tabel 5. Hasil Observasi Keaktifan Siswa Siklus II

\begin{tabular}{|l|c|c|}
\hline \multirow{2}{*}{\multicolumn{1}{|c|}{ Aspek Aktivitas }} & \multicolumn{2}{c|}{ Jumlah Siswa } \\
\cline { 2 - 3 } & Aktif & Tidak Aktif \\
\hline Aktifitas dalam bertanya & 20 siswa & 24 siswa \\
\hline Aktifitas dalam menjawab & 33 siswa & 11 siswa \\
\hline Aktifitas dalam berpendapat & 10 siswa & 34 siswa \\
\hline Aktifitas dalam merangkum & 39 siswa & 5 siswa \\
\hline Rata-rata & 25.5 & 18.5 \\
\hline Rata-rata persentase & $58 \%$ & $42 \%$ \\
\hline
\end{tabular}

Berdasarkan tabel di atas dapat diketahui bahwa pada siklus II, aktivitas siswa dalam proses pembelajaran semakin membaik dan meningkat. Kondisi ini ditandai oleh jumlah siswa yang aktif mencapai 58\% dan siswa yang tidak aktif dalam pembelajaran 42\%. Hal ini dikarenakan rata-rata siswa sudah memiliki keberanian untuk mengemukakan pertanyaan-pertanyaan dan menjawab pertanyaan dari guru, meskipun peningkatan keaktifan siswa dalam mengemukakan pendapat tidak terlalu signifikan dibanding siklus I.

Setelah melaksanakan proses pembelajaran dengan menerapkan penerapan model pembelajaran tebak kata, pada akhir siklus I dilaksanakan evaluasi pembelajaran. Perolehan nilai rata-rata siswa pada siklus I adalah 66,02, di mana sebanyak 4 siswa memperoleh nilai dengan predikat 'Sangat Baik' yaitu di atas 85, sedangkan nilai terendah yang diperoleh siswa adalah 40 sebanyak tiga siswa. Perolehan ketuntasan belajar klasikal pada siklus I adalah 66\%. Merujuk pada data hasil observasi aktivitas siswa dalam proses belajar mengajar siklus I, dapat disimpulkan bahwa selama kegiatan pembelajaran, siswa kurang aktif. Persentase siswa yang aktif dan yang tidak aktif dalam pembelajaran adalah sama besar, yaitu 50\%, sehingga peneliti berkesimpulan bahwa tindakan lanjutan harus diberikan pada siswa melalui pelaksanaan pembelajaran siklus II.

Pembelajaran pada siklus II dilaksanakan dengan tujuan untuk lebih mengaktifkan siswa dalam proses belajar mengajar di kelas. Evaluasi terhadap hasil belajar siswa diberikan pada akhir pembelajaran siklus II. Perolehan nilai rata-rata siswa pada siklus II adalah 72,27, di mana sebanyak 7 siswa memperoleh nilai dengan predikat 'Sangat Baik' 
yaitu di atas 85 , sedangkan nilai terendah adalah 45 dan hanya diperoleh oleh 3 siswa. Perolehan ketuntasan belajar klasikal pada siklus II mengalami peningkatan dari $66 \%$ pada siklus I meningkat menjadi 78\%. Sampai pada tahap pembelajaran siklus II, sebanyak 34 siswa memperoleh nilai minimal 65 dari total 44 siswa. Secara umum dapat disimpulkan bahwa hasil penelitian tindakan kelas yang dilaksanakan pada siklus II, untuk ketuntasan secara klasikal termasuk ke dalam sangat baik karena mampu mencapai 78\%. Persentase ketuntasan ini telah melewati standar ketuntasan klasikal minimal 75\%, dengan telah tercapainya hasil tersebut maka penelitian ini dihentikan. Selama pelaksanaan pembelajaran pada siklus I dan siklus II, dari hasil pengamatan dapat diketahui telah terjadi perubahan pada siswa ke arah yang lebih baik karena terjadi peningkatan hasil belajar siswa

\section{KESIMPULAN}

Berdasarkan hasil penelitian dan pembahasan seperti yang telah diuraikan pada bab sebelumnya maka dapat disimpulkan bahwa penerapan model pembelajaran tebak kata dapat meningkatkan hasil belajar biologi siswa kelas VIII SMP Kristen 1 YPK Malang pada pokok bahasan sistem pencernaan pada manusia. Peningkatan ini ditandai dengan meningkatnya ketuntasan belajar klasikal dari siklus ke siklus, di mana persentase jumlah siswa yang tuntas belajar pada siklus I hanya mencapai $66 \%$, selanjutnya pada siklus II meningkat menjadi $78 \%$ siswa tuntas belajar dan telah mencapai target ketuntasan belajar klasikal minimum $75 \%$.

\section{SARAN}

1. Bagi siswa: Diharapkan agar siswa selalu memperhatikan anjuran guru dan melaksanakan tugas dengan baik guna meningkatkan pemahaman dan hasil belajar akademik; dan Diharapkan agar siswa lebih disiplin dalam memanfaatkan waktu, terutama waktu untuk belajar, baik saat berada di kelas maupun di luar kelas, misalnya selalu aktif dalam mencari informasi-informasi terkini mengenai aspek-aspek pembelajaran guna meningkatkan pengetahuan, pemahaman, dan hasil belajar sehingga menjadi lebih baik lagi.

2. Bagi guru: Merujuk pada hasil penelitian, oleh karena model pembelajaran tebak kata yang diterapkan dalam penelitian ini mampu meningkatkan hasil belajar biologi siswa pada pokok bahasan sistem pencernaan pada manusia, maka disarankan kepada guru agar menggunakan model pembelajaran tersebut dalam proses belajar mengajar biologi di kelas, khususnya untuk pokok bahasan sistem pencernaan pada manusia.

3. Bagi peneliti serupa: Diharapkan penggunaan populasi atau sampel dalam jumlah yang lebih besar dan divariasikan dengan kelompok kontrol bagi peneliti yang meneliti masalah serupa sehingga dapat diketahui hasil penelitian yang lebih baik lagi 


\section{DAFTAR PUSTAKA}

Arifin. 2010. Penelitian Pendidikan: Pendekatan Kuantitatif \& Kualitatif. Lilin Persada Press. Yogyakarta.

Chatarina, Tri Anni. 2007. Psikologi Belajar. UNNES Press. Semarang.

Darsono, M; A. Sugandhi; Martensi, Dj.; R. K. Sutadi \& Nugroho. 2000. Belajar dan Pembelajaran. IKIP Semarang Press. Semarang.

Departemen Pendidikan Nasional. 2004. Pedoman Analisis Hasil Evaluasi Belajar. Jakarta.

Hamalik, O. 2001. Proses Belajar Mengajar. Bumi Aksara. Jakarta:

Kurniastuti. 2006. Meningkatkan Hasil Belajar Biologi Pokok Bahasan Ekosistem Melalui Pendekatan Pembelajaran CTL (Contextual Teaching and Learning) pada Siswa Kelas VII Semester Genap SMP Negeri I Doro Kabupaten Pekalongan TP. 2004/2005. Skripsi. MIPA UNNES. Semarang:

Maslihah, Siti. 2011. Studi Komparasi Model Think Pair and Share (TPS) dan Model Pembelajaran Berbasis Proyek Terhadap Hasil Belajar Siswa Kelas VIII Pada Mata Pelajaran IPS Materi Sejarah Di SMP Negeri 5 Kudus Tahun Ajaran 2010/2011. Skripsi. UNNES. Semarang.

Sudjana, Nana. 2001. Dasar-Dasar Proses Belajar Mengajar. CV. Sinar Baru. Bandung.

Sudjana, Nana. 2000. Dasar-dasar Proses Belajar Mengajar. Sinar Bumi Agensindo. Bandung

Suprijono, Agus. 2009. Cooperative Learning Teori dan Aplikasi Paikem. Pustaka belajar. Yogyakarta.

Trianto. 2007. Model-model Pembelajaran Inovatif Berorientasi Konstruktivistik. Prestasi Pustaka. Jakarta.

Widodo, Wiwid. 2009. Model Pembelajaran Tebak Kata. http://wyw1d.wordpress. com.2009/11/14/model-pembelajaarn-tebak-kata.htm.l (Online) diakses $21 / 1 / 2012$ 